\title{
Application Multicriteria Decision Making Method to Determine the Placement of Power Distribution System
}

\author{
Gholamreza Jandaghi, Fatemeh Alah Akbari \\ Faculty of Management and Accounting, College of Farabi, University of Tehran, Tehran, Iran \\ Email address: \\ jandaghi@ut.ac.ir (G. Jandaghi), f.alahakbari@ut.ac.ir (F. A. Akbari)

\section{To cite this article:} \\ Gholamreza Jandaghi, Fatemeh Alah Akbari. Application Multicriteria Decision Making Method to Determine the Placement of Power \\ Distribution System. American Journal of Theoretical and Applied Business. Vol. 3, No. 2, 2017, pp. 23-30. \\ doi: $10.11648 /$ j.ajtab.20170302.12
}

Received: December 1, 2016; Accepted: May 15, 2017; Published: June 16, 2017

\begin{abstract}
Exploring the historical path of theories and placement models indicates the deployment in terms of effective criterions and useful approaches in various industries. The distribution of electricity is important because of different reasons and all the efforts are for the sake of decreasing casualties of this network and supplying customer needs. The following research tries to come up with a model for placement the electricity distributer posts and that only happens with the recognition of effective priorities. The following research has used measurement to collect data and samplings were executed with a nonaccidental and judgmental method. After asking 11 experts the research detected six criterions and 28 subsets. These criterions are as follows: Technical, Economical, Exploitation, Executive Surveillance and Biological. In the beginning there was a dual comparison between the factors and the effectiveness of these factors was determined by AHP approach. Then with the assessment of all the nominated factors and performing a matrix, some of the Fuzzy TOPSIS were used. In the end the following model was executed by EXCEL and a factor has been determined as the final solution.
\end{abstract}

Keywords: Location Selection, Power Distribution System, Analytical Hierarchy Process, Fuzzy TOPSIS

\section{History and Literature}

The power industry is considered one of the most vital industries of a country. In the meantime, the electricity distribution networks are the confluence of electrical industry subscribers and the bugs of distribution system in the industry is considered all electricity industry problems from the perspective of consumers. Given that $53 \%$ of power industry investments relate to the distribution sector and the lack of proper design and planning system, and setting goals without projects control follow the cause of loss to national wealth, power loss, and dissatisfaction and pessimism of subscribers. Therefore, monitoring and evaluation are strongly felt in distributed systems. Generally the main goal of the design and development of electricity distribution networks is the respond to growing electricity consumption with maximum economic efficiency in a way that it does not violate the limitations of a system. Many elements in distribution networks that follow many decision variables have caused problems for designing and developing these networks (Roshan Milani, 2002).
Despite the importance of the subject, the most important challenge is the establishment of power distribution substations in optimal places which, in addition to reducing installation costs, it results in better coverage for subscribers in the region. Thus, the optimal locating of power distribution substations is one of the most important principles in order to increase their efficiency.

One of the important information that helps to achieve this goal is prioritizing candidate sites that are including greatest need to establish the power distribution substation. To achieve the target, it is required to choose a good place.

\section{Locating}

Studies about the locating have a long research history and are related to many different research areas, including research in operations, industrial engineering, geography, economics, computer science, mathematics, marketing, power engineering and urban planning (Cheng \& $\mathrm{Li}, 2004)$. Also, various methods have been developed for this critical issue (Tsung-Yu, Chia-Lun, \& Mei-Chyi, 2008). The basic 
methods that are used in locating are summarized as follows: (Kahraman, Ruan, \& Doğan, 2003; Tsung-Yu et al., 2008).

a. Factors ranking (Chase \& Aquilano, 1995).

b. Center of Gravity (Chase \& Aquilano, 1995).

c. Method of Delphi analysis (Chase \& Aquilano, 1995).

d. Analog procedure (Applebaum, 1968).

e. AHP (Badri, 1999).

f. Multiple regression analysis (Satani et al., 1998).

g. GIS (Zhang, Johnson, \& Sutherland, 2011).

h. Artificial neural networks, mathematical programming techniques including dynamic programming (Canel, Khumawala, Law, \& Loh, 2001).

Non-Linear Programming (Nanthavanij \& Yenradee, 1999).

Integer programming (Melkote \& Daskin, 2001).

Quadratic programming (Comley, 1995).

The first scientific approach with the locating was considered by mathematicians for centuries. For example, the locating of unit device, before the seventeenth century has been in the work of mathematicians. Of course, mathematicians in the past were not involved with locating problems independently. But, they attempted to resolve the problems of extreme functions (minimum or maximum functions) with this problem. Economists have suggested many theories in relation to locating economic units that in this study, we try to point out some of them.

Lanhart in 2002 has presented his theory that he has considered great importance to transportation. From Lanhart's point of view, the ideal spot to deploy the industry is the point in which the total transportation costs will be possible in minimal including raw materials, finished products and fuel sources. In his spatial analysis, he has used the locating triangle to locate. Alfred Weber (2191) has insisted on minimizing costs, which include transportation, labor and industrial aggregation in determining the location of an economic plan. Tred Plander in 2153 has focused on the relationship between the cost of transport and the distance as well as the difference of shipping rates in the locating issue.

Agust Loucg, in the year 2149 has considered the impact of demand on choosing the right location, and this was something that did not pay attention to it in the previous theories. According to Agust Loucg, the establishment at minimum cost does not necessarily mean in maximum profit. Instead, production units sell more and earn more, and they will be able to earn more profit. He said in his theory that each manufacturer is looking to expand its sphere of influence in the market (Mehrabi Koshki, 2003). From another point of view, we can divide locating theories of the second period into two categories: one category includes conditions that create facilities from two-dimensional continues space or any $\mathrm{x}$ and $\mathrm{y}$. These issues are mainly studied as k-median location problem.

\section{Decision Making}

Decision-making is a process that involves choosing a way or method among two or more available methods. The decision means the conscious choice that allows the person to examine the specific behavior and attitude of the set, according to a given set of conditions, and then an option will be accepted and implemented. (Yurdakul \& Ic, 2004)

Rarely, a person or organization decides on the basis of a benchmark. Most decisions are multi-criteria, and they were considered by managers since the Second World War and optimization problems, according to an objective function. While today, taking into account the criteria, more attention has been paid to optimization problems (Momeni, 2008). MCDM Models are divided into two categories of multiobjective decision making MADM and multi-attribute decision making MODM, so that, MODM models are used to design. However, MADM models are used in order to select the preferred option (Asgharpoor, 2010).

One of the most prominent multi-criteria decision-making approaches are analytic hierarchy process approach, which focuses on obtaining the relative weights of factors and the overall value of each option based on the weights. (Torfi, Farahani, \& Rezapour, 2010) In comparison with other methods of multi-criteria decision, the AHP method is widely used in multi-criteria decision-making and in many other issues from the decision so successfully (Torfi et al., 2010.)

TOPSIS, other multi-criteria decision-based approach is the best option that has the shortest distance of the positive ideal solution (option) and the longest distance of the solution (option) of negative ideal. The positive ideal solution is solutions that maximizes profit criteria and minimize cost criteria and maximize negative ideal solution of cost criterion and minimizes the profit criterion. (Kelemenis \& Askounis, 2010)

\section{Research Methodology}

In this study, to collect the required data, questionnaires and interviews were used. The number of interviews Group was 11 experts in the field of electricity and to prioritize places, in this study, and to avoid ambiguity caused by uncertainty in the decision, the triangular fuzzy numbers were used. With the use of GAHP method, the weighting was done and finally, by using a fuzzy TOPSIS ranking was done. The above study steps are as follows:

a. Identify the required criteria and weighting them by the Analytic Hierarchy Process

b. Enter the calculated weight with a Fuzzy Topsis method to prioritize locations for power distribution substation

c. Categories of candidate locations for construction of power distribution substation with the output of the Fuzzy Topsis method

\section{Identify Needed Criteria}

In the first stage, with library studies and literature available on the subject, criteria and sub-criteria affecting the ranking of candidate sites for the construction of power distribution substations were identified. The first stage questionnaire consists of three decent ranges; it is relatively 
good and is not suitable. Then by filling the first stage questionnaire that its example is available in Appendix 2 and interviewing with 11 experts of electricity in Qom, criteria and sub-criteria were chosen, which include (see Figure 1):

1. Criteria related to technical dimension (Akbari Foroud, Seifi, Golsaz Shirazi, \& Asiaei, 2011; Mehrabi, Koshki, 2003)

2. Criteria related to the economic dimension (Akbari Foroud et al., 2011; Mehrabi Koshki, 2003)
3. Criteria related to the utilization factor (Roshan Milani, 2002)

4. Criteria related to the Monitoring - Executive dimension (Mehrabi Koshki, 2003; Roshan Milani, 2002)

5. Criteria related to the environmental dimension (Roshan Milani, 2002)

6. Criteria related to the computing

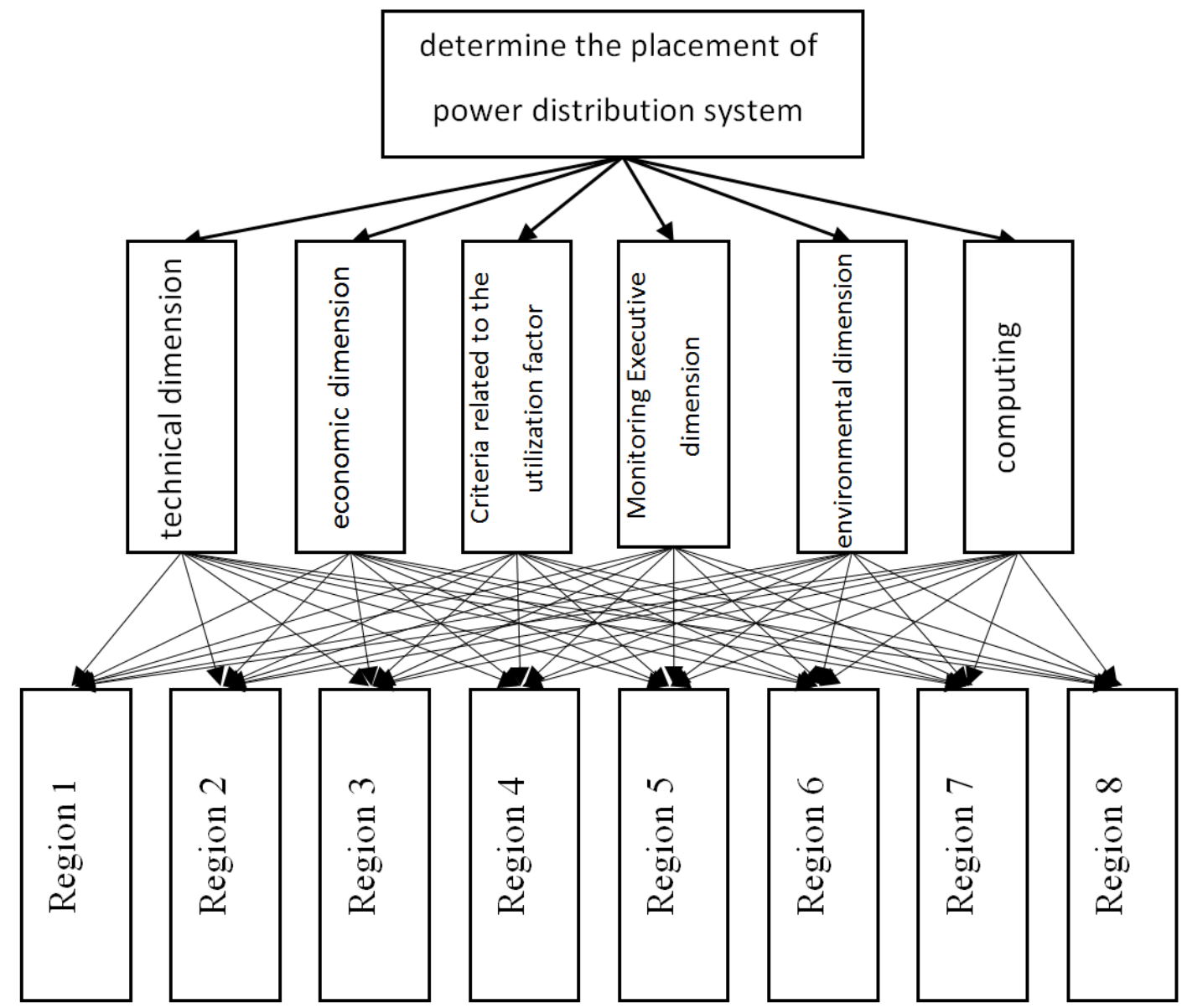

Figure 1. Decision tree hierarchy locating.

\section{Weighting the Criteria of the Study}

To weight the criteria for the study ${ }^{1}$, the Analytic Hierarchy Process was used. AHP Process has been introduced and used for the first time by Tomas Saaty. This model is the method to decide and choose the best options, especially when there are several indicators and criteria for decision-making (Saaty, 1997). Analytical Hierarchy Process (AHP) is a logical framework that facilitates the understanding and analyzing the complex decisions by decomposing it into a hierarchical structure. (Mansor et al., 2006)

\section{Group Analytical Hierarchy Process (GAHP)}

Step 1. Calculate the weighted sum vector: multiply paired comparison matrix by the column vector "relative weight"

1 Weighted sum Vector $=$ WSV and call the new vector, the weighted sum vector.

Step 2. Calculate Consistency vector: divide elements of the weighted sum vector by the relative priority vector. Vector is called Consistency vector.

Step 3. Obtaining $\lambda_{\max }$ gives the average elements of $\lambda_{\max }$ Consistency vector.

Step 4. Calculate the Consistency index $=\mathrm{CI}$ : Consistency index for the group AHP is defined as follows:

$$
C I=\frac{\lambda_{\max }-n}{n}
$$

$\mathrm{n}$ is the number of options on an issue

Step 5. Calculate the ratio of consistency: consistency ratio is obtained by dividing the consistency index to random index=RI.

$$
C R=\frac{C . I}{R . I}
$$


The consistency ratio 0.1 or less expresses the consistency in comparisons; random index derived from the chart below (Azar\& Rajabzadeh, 2002).

Prioritize sites for construction of fuzzy topsis power distribution substation

TOPSIS Method is broadly used in order to rank issues in real conditions. The major limitation of TOPSIS method is inability to solve vague and uncertain problems in the process of decision-making (Yu, 2002). In order to overcome this limitation, we can use fuzzy set theory with TOPSIS method that allows decision makers to determine qualitative, incomplete, non-obtainable information and detail facts with decision models. (Dağdeviren, Yavuz, \& K1lınç, 2009; Kulak, Durmuşoğlu, Gumus, 2009\& Kahraman, 2005) Thus, the fuzzy TOPSIS method is more appropriate and more effective than TOPSIS.

In general, algorithms for solving multi-criteria multiindex decision-making issues are provided below by fuzzy set approach.

a. The first step- Identify criteria to evaluate options, allocate appropriate linguistic variables for weighting the criteria and the allocation of points or the value of each option based on the criteria in the form of linguistic variables.

b. The second step- Constructing The Normalized Fuzzy Decision Matrix (NFDM)

c. The third step- Constructing The Weighted Normalized Fuzzy Decision Matrix (WNFDM)

d. The fourth step- Determine the positive ideal solution and fuzzy negative ideal solution

e. The fifth step-Calculate the distance of each option from the positive ideal solution and negative ideal solution

f. The sixth step- Calculate the proximity factor of each option

g. The seventh step- Ranking the options according to the calculated proximity factor

h. In the following, each of the above steps is described.

The first step- By using Group Analytical Hierarchy Process (GAHP) in the previous section, weight of each criterion has been achieved.

The second step: Create a Normalized Fuzzy Decision Matrix (NFDM)

According to a previous step, importance or weight of each criterion and ranking the options will be calculated based on each criterion as follows. (Chu, 2002)

$$
\begin{gathered}
x_{i j}=\frac{1}{k}(\times)\left[x_{i j}^{1}(+) x_{i j}^{2}(+) \ldots(+) x_{i j}^{k}\right] ; a_{i j}=\sum_{t=1}^{k} a_{i j}^{t} /{ }_{k} ; b_{i j}=\sum_{t=1}^{k} b_{i j}^{t} /{ }_{k} ; c_{i j}=\sum_{t=1}^{k} a_{i j}^{t} / k \\
w_{j}=\frac{1}{k}(\times)\left[w_{j}^{1}(+) w_{j}^{2}(+) \ldots(+) w_{j}^{k}\right] ; e_{j}=\sum_{t=1}^{k} e_{j}^{t} /_{k} ; f_{j}=\sum_{t=1}^{k} f_{j}^{t} /_{k} ; g_{j}=\sum_{t=1}^{k} g_{j}^{t} /_{k}
\end{gathered}
$$

As mentioned above, A Fuzzy Multicriteria Group Decision-Making Problem can be briefly shown in the decision matrix below.

$$
D M=\left[\begin{array}{cccc}
x_{11} & x_{12} & \ldots & x_{1 n} \\
x_{21} & x_{22} & \ldots & x_{2 n} \\
\cdot & \cdot & \ldots & \cdot \\
x_{m 1} & x_{m 2} & \ldots & x_{m n}
\end{array}\right] ; \tilde{W}=\left[w_{1}, w_{2}, \ldots, w_{n}\right]
$$

In order to ensure compatibility between the mean of scores and the mean of weights, they must be normalized to become comparable scales. To avoid the complexity of the formula used for the classical TOPSIS normalization (Soft Euclidean), here the scale or soft line will be used to convert the scales on various criteria. As a result, normalized Fuzzy decision matrix $(\sim \mathrm{U})$ will be calculated (Chu, 2002). This matrix is calculated as follows.

$$
\begin{gathered}
c_{j}^{*}=\operatorname{Max}_{i} c_{i j}, j \in B ; \\
a_{j}^{-}=\operatorname{Min}_{i} a_{i j}, j \in C \\
\widetilde{u_{\imath \jmath}}=\left(\frac{a_{i j}}{c_{j}^{*}}, \frac{b_{i j}}{c_{j}^{*}}, \frac{c_{i j}}{c_{j}^{*}}\right), j \in B ;
\end{gathered}
$$

The fifth step: Calculate the distance of each option from the positive ideal solution and negative ideal solution.

The distance of options will be calculated from $A^{*}$ and $A$ as follows:

$$
d_{i}^{*}=\sum_{j=1}^{n} d\left(\tilde{v}_{i j}, \tilde{v}_{j}^{*}\right), i=1, \ldots, m,
$$




$$
d_{i}^{-}=\sum_{j=1}^{n} d\left(\tilde{v}_{i j}, \tilde{v}_{j}^{-}\right), i=1, \ldots, m,
$$

$d_{i}^{*}$ is the distance of every option from a positive ideal solution and $d_{i}^{-}$is the distance of every option from a negative ideal solution.

The sixth step: Calculate the proximity factor for each option

The proximity factor is calculated based on $d_{i}^{-}$and $d_{i}^{*}$ respectively as follows.

$$
C C_{i}=\frac{d_{i}^{-}}{d_{i}^{*}+d_{i}^{-}}, A_{i}(i=1,2, \ldots, m)
$$

The seventh step: Ranking the options, given the calculated proximity coefficient

It is clear that, if options $A^{*}$ will be closer to $A_{i}$ or the positive ideal solution and will be further from $A$ - or the negative ideal solution, the proximity coefficient $c c$ i will tend towards one. Then, based on the proximity coefficient, the rating of options can be done. In fact, the options that have more proximity coefficient, they will have higher rankings.

\section{Evaluation Results}

First phase: weighting the criteria by applying GAHP

Table 1. Final weights of criteria.

\begin{tabular}{lll}
\hline $\mathbf{C j}$ & $(\mathbf{W})$ \\
\hline Criteria related to technical dimension & $\mathrm{C} 1$ & $0 / 163$ \\
Criteria related to the economic dimension & $\mathrm{C} 2$ & $0 / 252$ \\
Criteria related to the utilization factor & $\mathrm{C} 3$ & $0 / 174$ \\
Criteria related to the Monitoring Executive dimension & $\mathrm{C} 4$ & $0 / 082$ \\
Criteria related to the environmental dimension & $\mathrm{C} 5$ & $0 / 107$ \\
Criteria related to the computing & $\mathrm{C} 6$ & $0 / 223$ \\
\hline
\end{tabular}

A questionnaire was designed to determine the weighting of criteria and sub-criteria by using pairwise comparisons. Then, it was completed by interviewing 11 experts of power in Qom. Finally, by using Group Analytical Hierarchy Process (GAHP), final weights of criteria were obtained that are shown in Table 1.

\section{Fitting FUZZY-TOPSIS Model}

Before using, the indices of model will be defined:

According to the equations that were mentioned in the second and third sections, quantities composed of $\mathrm{k}$ decisionmaking $\left(D_{1}, D_{2} \ldots D_{k}\right)$ which are responsible for assessing the m options $\left(A_{1}, A_{2} \ldots A_{m}\right)$ based on the $n$ criteria $\left(C_{1}, C_{2} \ldots C_{n}\right)$. Where $11=\mathrm{k}$ is the number of decision-makers and evaluators and $8=\mathrm{m}$ is the number of candidate sites options as well as $6=\mathrm{n}$ is the number of factors and subjective and qualitative criteria.

In this section, the collected data were employed in the extended equations and the results of each step are shown in anatomical tables.

In the second part of the questionnaire, each time, the decision maker rates, according to a benchmark, to all the eight options, by using linguistic variables, in the following 7 ranges, where, VP is very poor with triangular fuzzy values $(1,0,0), \mathrm{P}$ is poor with triangular fuzzy values $(3,1,0), \mathrm{MP}$ is moderate poor with triangular fuzzy values $(5,3,1), \mathrm{F}$ is "fair" with triangular fuzzy values $(7,5,3), \mathrm{MG}$ is equivalent to "medium Good" with triangular fuzzy values $(9,7,5), \mathrm{G}$ is equivalent to "good" with triangular fuzzy values $(01,9,7)$, and finally, the VG is equivalent to "very good" with triangular fuzzy values $(10,10,9)$. Therefore, the second part of the questionnaire contains 29 tables (for each criterion a table).

After reviewing the questionnaires, the summarized comments of 11 decision makers are in Tables 1 and 2 .

\begin{tabular}{|c|c|c|c|c|c|c|c|c|c|}
\hline Matrix decision & $\mathrm{C1}$ & & & $\mathrm{C2}$ & & & C3 & & \\
\hline A1 & $3 / 000$ & $4 / 455$ & $6 / 091$ & $3 / 091$ & $4 / 727$ & $6 / 636$ & $5 / 273$ & $7 / 091$ & $8 / 545$ \\
\hline $\mathrm{A} 2$ & 3/909 & $5 / 909$ & $7 / 727$ & $2 / 273$ & $4 / 091$ & $6 / 091$ & $3 / 727$ & $5 / 727$ & $7 / 636$ \\
\hline A3 & $4 / 636$ & $6 / 455$ & $8 / 000$ & $3 / 455$ & $5 / 091$ & $6 / 818$ & $3 / 636$ & $5 / 273$ & $6 / 909$ \\
\hline A4 & $2 / 455$ & $4 / 182$ & $6 / 091$ & $2 / 182$ & $3 / 545$ & $5 / 364$ & $3 / 636$ & $5 / 455$ & $7 / 091$ \\
\hline A5 & $2 / 818$ & $4 / 273$ & $6 / 091$ & $2 / 273$ & $3 / 909$ & $5 / 636$ & $3 / 364$ & $4 / 909$ & $6 / 545$ \\
\hline A6 & $5 / 182$ & $6 / 727$ & $8 / 000$ & $4 / 091$ & $5 / 909$ & $7 / 545$ & $4 / 545$ & $6 / 182$ & $7 / 545$ \\
\hline A7 & $4 / 273$ & $6 / 000$ & $7 / 636$ & $3 / 636$ & $5 / 455$ & $7 / 182$ & $4 / 818$ & $6 / 455$ & $7 / 818$ \\
\hline
\end{tabular}

Table 2. Fuzzy decision making matrix.

\begin{tabular}{|c|c|c|c|c|c|c|c|c|c|}
\hline Matrix decision & $\mathrm{C4}$ & & & C5 & & & C6 & & \\
\hline A1 & $4 / 909$ & $6 / 000$ & $6 / 909$ & $5 / 182$ & $7 / 000$ & $8 / 364$ & $4 / 455$ & $6 / 273$ & $8 / 000$ \\
\hline A2 & $4 / 818$ & $6 / 364$ & $7 / 727$ & $3 / 636$ & $5 / 455$ & $7 / 091$ & $4 / 545$ & $6 / 182$ & $7 / 636$ \\
\hline A3 & $5 / 818$ & $7 / 455$ & $8 / 545$ & $3 / 818$ & $5 / 455$ & $7 / 091$ & $5 / 455$ & $7 / 091$ & $8 / 273$ \\
\hline A4 & $4 / 727$ & $6 / 091$ & $7 / 273$ & $6 / 000$ & $7 / 455$ & $8 / 364$ & $3 / 818$ & $5 / 455$ & $7 / 182$ \\
\hline A5 & $4 / 545$ & $6 / 091$ & $7 / 455$ & $1 / 818$ & $2 / 909$ & $4 / 455$ & $5 / 818$ & $7 / 455$ & $8 / 545$ \\
\hline A6 & $4 / 818$ & $6 / 182$ & $7 / 273$ & $4 / 182$ & $5 / 818$ & $7 / 273$ & $6 / 545$ & $8 / 091$ & $9 / 000$ \\
\hline A7 & $6 / 091$ & $7 / 818$ & $8 / 909$ & $4 / 000$ & $5 / 909$ & $7 / 545$ & $4 / 182$ & $6 / 000$ & $7 / 727$ \\
\hline
\end{tabular}

Table 2. Continued.

The second step: Create a normalized fuzzy decision matrix 
The calculation of this step has been performed according to equation 3 in this study and the results are shown in Table 3 :

Table 3. Normalized fuzzy decision matrix.

\begin{tabular}{|c|c|c|c|c|c|c|c|c|c|}
\hline $\begin{array}{l}\text { normalized fuzzy } \\
\text { decision matrix }\end{array}$ & C1 & & & $\mathrm{C} 2$ & & & C3 & & \\
\hline A1 & $0 / 301$ & $0 / 449$ & $0 / 617$ & $0 / 326$ & $0 / 504$ & $0 / 712$ & $0 / 532$ & $0 / 720$ & $0 / 875$ \\
\hline $\mathrm{A} 2$ & $0 / 397$ & $0 / 601$ & $0 / 787$ & $0 / 237$ & $0 / 436$ & $0 / 657$ & $0 / 378$ & $0 / 587$ & $0 / 788$ \\
\hline A3 & $0 / 470$ & $0 / 656$ & $0 / 814$ & $0 / 368$ & $0 / 550$ & $0 / 744$ & $0 / 375$ & $0 / 548$ & $0 / 721$ \\
\hline A4 & $0 / 248$ & $0 / 423$ & $0 / 617$ & $0 / 230$ & $0 / 378$ & $0 / 577$ & $0 / 367$ & $0 / 551$ & $0 / 720$ \\
\hline A5 & $0 / 292$ & $0 / 441$ & $0 / 627$ & $0 / 242$ & $0 / 427$ & $0 / 622$ & $0 / 351$ & $0 / 515$ & $0 / 689$ \\
\hline A6 & $0 / 528$ & $0 / 687$ & $0 / 818$ & $0 / 429$ & $0 / 627$ & $0 / 813$ & $0 / 458$ & $0 / 630$ & $0 / 775$ \\
\hline A7 & $0 / 433$ & $0 / 610$ & $0 / 778$ & $0 / 386$ & $0 / 582$ & $0 / 773$ & $0 / 485$ & $0 / 654$ & $0 / 801$ \\
\hline A8 & $0 / 408$ & $0 / 603$ & $0 / 780$ & $0 / 377$ & $0 / 599$ & $0 / 811$ & $0 / 503$ & $0 / 683$ & $0 / 837$ \\
\hline
\end{tabular}

Table 3. Continued.

\begin{tabular}{|c|c|c|c|c|c|c|c|c|c|}
\hline $\begin{array}{l}\text { normalized fuzzy } \\
\text { decision matrix }\end{array}$ & $\mathrm{C} 4$ & & & C5 & & & C6 & & \\
\hline A1 & $0 / 492$ & $0 / 607$ & $0 / 708$ & $0 / 521$ & $0 / 706$ & $0 / 846$ & $0 / 451$ & $0 / 638$ & $0 / 821$ \\
\hline $\mathrm{A} 2$ & $0 / 485$ & $0 / 641$ & $0 / 784$ & $0 / 367$ & $0 / 551$ & $0 / 717$ & $0 / 458$ & $0 / 630$ & $0 / 784$ \\
\hline A3 & $0 / 585$ & $0 / 754$ & $0 / 873$ & $0 / 388$ & $0 / 556$ & $0 / 723$ & $0 / 546$ & $0 / 716$ & $0 / 844$ \\
\hline A4 & $0 / 476$ & $0 / 618$ & $0 / 746$ & $0 / 603$ & $0 / 751$ & $0 / 844$ & $0 / 382$ & $0 / 549$ & $0 / 731$ \\
\hline A5 & $0 / 471$ & $0 / 636$ & $0 / 782$ & $0 / 187$ & $0 / 299$ & $0 / 458$ & $0 / 594$ & $0 / 766$ & $0 / 885$ \\
\hline A6 & $0 / 483$ & $0 / 621$ & $0 / 736$ & $0 / 424$ & $0 / 592$ & $0 / 741$ & $0 / 660$ & $0 / 820$ & $0 / 921$ \\
\hline A7 & $0 / 622$ & $0 / 804$ & $0 / 923$ & $0 / 410$ & $0 / 605$ & $0 / 773$ & $0 / 430$ & $0 / 619$ & $0 / 801$ \\
\hline A8 & $0 / 560$ & $0 / 711$ & $0 / 839$ & $0 / 406$ & $0 / 574$ & $0 / 723$ & $0 / 551$ & $0 / 729$ & $0 / 875$ \\
\hline
\end{tabular}

The third step: Create weighted normalized fuzzy decision matrix (WNFDM)

The calculation of this step has been performed according to equation 66 in this study and the results are shown in Table 4:

Table 4. Weighted normalized decision matrix.

\begin{tabular}{|c|c|c|c|c|c|c|c|c|c|}
\hline $\begin{array}{l}\text { Weighted normalized } \\
\text { decision matrix }\end{array}$ & C4 & & & C5 & & & C6 & & \\
\hline A1 & $0 / 049$ & $0 / 073$ & $0 / 101$ & $0 / 082$ & $0 / 127$ & $0 / 179$ & $0 / 092$ & $0 / 125$ & $0 / 152$ \\
\hline $\mathrm{A} 2$ & $0 / 065$ & 0/098 & $0 / 128$ & $0 / 060$ & $0 / 110$ & $0 / 165$ & $0 / 066$ & $0 / 102$ & $0 / 137$ \\
\hline A3 & $0 / 077$ & $0 / 107$ & $0 / 133$ & $0 / 093$ & $0 / 138$ & $0 / 187$ & $0 / 065$ & $0 / 095$ & $0 / 125$ \\
\hline A4 & $0 / 040$ & $0 / 069$ & $0 / 101$ & $0 / 058$ & $0 / 095$ & $0 / 145$ & $0 / 064$ & $0 / 096$ & $0 / 125$ \\
\hline A5 & $0 / 048$ & $0 / 072$ & $0 / 102$ & $0 / 061$ & $0 / 108$ & $0 / 156$ & $0 / 061$ & $0 / 090$ & $0 / 120$ \\
\hline A6 & $0 / 086$ & $0 / 112$ & $0 / 133$ & $0 / 108$ & $0 / 158$ & $0 / 205$ & $0 / 080$ & $0 / 109$ & $0 / 135$ \\
\hline A7 & $0 / 071$ & 0/099 & $0 / 127$ & $0 / 097$ & $0 / 147$ & $0 / 194$ & $0 / 084$ & $0 / 114$ & $0 / 139$ \\
\hline A8 & $0 / 066$ & $0 / 098$ & $0 / 127$ & $0 / 095$ & $0 / 151$ & $0 / 204$ & $0 / 087$ & $0 / 119$ & $0 / 145$ \\
\hline
\end{tabular}

Table 4. Continued.

\begin{tabular}{|c|c|c|c|c|c|c|c|c|c|}
\hline $\begin{array}{l}\text { Weighted normalized } \\
\text { decision matrix }\end{array}$ & $\mathrm{C} 4$ & & & C5 & & & C6 & & \\
\hline A1 & $0 / 040$ & $0 / 050$ & $0 / 058$ & $0 / 056$ & $0 / 076$ & $0 / 091$ & $0 / 100$ & $0 / 142$ & $0 / 183$ \\
\hline $\mathrm{A} 2$ & $0 / 040$ & $0 / 052$ & $0 / 064$ & $0 / 039$ & $0 / 059$ & $0 / 077$ & $0 / 102$ & $0 / 140$ & $0 / 175$ \\
\hline A 3 & $0 / 048$ & $0 / 062$ & $0 / 071$ & $0 / 042$ & $0 / 059$ & $0 / 077$ & $0 / 122$ & $0 / 160$ & $0 / 188$ \\
\hline A4 & $0 / 039$ & $0 / 051$ & $0 / 061$ & $0 / 065$ & $0 / 080$ & $0 / 090$ & $0 / 085$ & $0 / 123$ & $0 / 163$ \\
\hline A5 & $0 / 039$ & $0 / 052$ & $0 / 064$ & $0 / 020$ & $0 / 032$ & $0 / 049$ & $0 / 132$ & $0 / 171$ & $0 / 197$ \\
\hline A6 & $0 / 039$ & $0 / 051$ & $0 / 060$ & $0 / 045$ & $0 / 063$ & $0 / 079$ & $0 / 147$ & $0 / 183$ & $0 / 205$ \\
\hline A7 & $0 / 051$ & $0 / 066$ & $0 / 075$ & $0 / 044$ & $0 / 065$ & $0 / 083$ & 0/096 & $0 / 138$ & $0 / 179$ \\
\hline A8 & $0 / 046$ & $0 / 058$ & $0 / 069$ & $0 / 043$ & $0 / 061$ & $0 / 077$ & $0 / 123$ & $0 / 163$ & $0 / 195$ \\
\hline
\end{tabular}

The fourth step: Determine the fuzzy positive ideal solution and negative ideal solution

The calculation of the positive ideal solution and negative ideal solutions will be:

$$
\begin{aligned}
& A^{*}=\{(1,1,1),(1,1,1),(1,1,1),(1,1,1),(1,1,1),(1,1,1)\} \\
& A^{-}=\{(0,0,0),(0,0,0),(0,0,0),(0,0,0),(0,0,0),(0,0,0)\}
\end{aligned}
$$

The fifth step: Calculate the distance of each alternative from positive ideal solution and negative ideal solution

Table 5. Options distance the ideal solution both positive and negative.

\begin{tabular}{lll}
\hline Option & $\mathbf{A}^{+}$ & $\mathbf{A}^{-}$ \\
\hline A1 & $5 / 411$ & $0 / 617$ \\
A5 & $5 / 336$ & $0 / 687$ \\
A3 & $5 / 386$ & $0 / 641$ \\
A4 & $5 / 486$ & $0 / 543$ \\
A5 & $5 / 478$ & $0 / 550$ \\
A6 & $5 / 360$ & $0 / 666$ \\
A7 & $5 / 380$ & $0 / 646$ \\
A8 & $5 / 443$ & $0 / 587$ \\
\hline
\end{tabular}


The sixth step: Calculate the proximity coefficient for each option

Table 6. Positive and negative ideal interval options and proximity of these.

\begin{tabular}{llll}
\hline Option & $\mathbf{d}_{\mathbf{i}}^{*}$ & $\mathbf{d}_{\mathbf{i}}^{-}$ & $\mathbf{C C j}$ \\
\hline A1 & $5 / 408$ & $0 / 594$ & $0 / 099$ \\
A2 & $5 / 358$ & $0 / 651$ & $0 / 108$ \\
A3 & $5 / 384$ & $0 / 625$ & $0 / 104$ \\
A4 & $5 / 484$ & $0 / 516$ & $0 / 086$ \\
A5 & $5 / 475$ & $0 / 513$ & $0 / 086$ \\
A6 & $5 / 441$ & $0 / 565$ & $0 / 094$ \\
A7 & $5 / 378$ & $0 / 627$ & $0 / 104$ \\
A8 & $5 / 333$ & $0 / 669$ & $0 / 111$ \\
\hline
\end{tabular}

The seventh step: Ranking the options, given the calculated proximity coefficient

According to the calculated proximity coefficients in the previous step, for every 8 options and compare those, the ranking of the options are as follows:

$$
\left\{\mathrm{A}_{5}\right\}>\left\{\mathrm{A}_{4}\right\}>\left\{\mathrm{A}_{2}\right\}>\left\{\mathrm{A}_{1}\right\}>\left\{\mathrm{A}_{3}\right\}>\left\{\mathrm{A}_{7}\right\}>\left\{\mathrm{A}_{8}\right\}>\left\{\mathrm{A}_{6}\right\}
$$

What is certain, if the option will be closer to $A^{*}$ or positive ideal solution, and will be further from $A^{-}$or negative ideal solution, the proximity coefficient will tend to one. In fact, the options with more value will have higher rankings.

Thus, the maximum amount, meaning 0.1 is characteristic of the solution. That is, among the eight options, the answer will be "Five as shown in table 7 . In other words, we have:

Table 7. The optimum location.

\begin{tabular}{lll}
\hline Location candidate selection & Region & Option \\
\hline Del Azar Blv & Five & A5 \\
\hline
\end{tabular}

\section{Discussion and Conclusion}

More projects that have been done in the country on locating have been done either based on the MADM methods or shipping and goal programming model, or by use of GIS. Each of these methods has its own benefits. For example, the GIS method is an appropriate method due to the complexity of the urban fabric, but it is not able to apply all kinds of descriptive information appropriately in itself particularly qualitative factors. Shipping and goal programming models do not have much application, given the circumstances of this case.

Also, in this paper, it has been tried to use a method that both apply quantitative criteria and qualitative criteria appropriately. Moreover, in order to use the advantages and avoid disadvantages, the method of Fuzzy multi-attribute decision method has been used. Initially, to calculate weights, the AHP method was used and then, in order to rank the desired location, FTOPSIS method was used in combination, to select the optimal location. In fact, in this study, by using TOPSIS FUZZY method, candidate sites were ranked for the construction of power distribution substation according to known factors. Finally, the new integrated model could choose the best place of power distribution substation with checking all the criteria.

\section{References}

[1] Akbari Foroud, Asghar, Seifi, Hossin, Golsaz Shirazi, Mohammad Reza, \& Asiaei, Khodrahm. (2011). A Heuristic Algorithm for Ranking of Transmission and Subtransmission Expansion Plans. The Modares Journal of Electrical Engineering, 10 (2), 83-99.

[2] Applebaum, William. (1968). The analog method for estimating potential store sales. Guide to store location research, 3, 127-144.

[3] Asgharpoor, MJ. (2010). Group decision making and game theory with operations research approach. Tehran university publication.

[4] Azar, A, \& Rajabzadeh, A. (2002). Practical decision making (MADM approach). Tehran. Negah Publication, 94, 216-287.

[5] Badri, Masood A. (1999). Combining the analytic hierarchy process and goal programming for global facility locationallocation problem. International Journal of Production Economics, 62 (3), 237-248.

[6] Canel, Cem, Khumawala, Basheer M, Law, Japhett, \& Loh, Anthony. (2001). An algorithm for the capacitated, multicommodity multi-period facility location problem. Computers \& Operations Research, 28 (5), 411-427.

[7] Chase, Richard, \& Aquilano, Nicholas. (1995). Production and Operations Management. Chicago: Irwin.

[8] Cheng, Eddie WL, \& Li, Heng. (2004). Exploring quantitative methods for project location selection. Building and Environment, 39 (12), 1467-1476.

[9] Chu, Ta-Chung. (2002). Facility location selection using fuzzy TOPSIS under group decisions. International journal of uncertainty, fuzziness and knowledge-based systems, 10 (06), $687-701$.

[10] Comley, Warwick J. (1995). The location of ambivalent facilities: Use of a quadratic zero-one programming algorithm. Applied mathematical modelling, 19 (1), 26-29.

[11] Dağdeviren, Metin, Yavuz, Serkan, \& Kılınç, Nevzat. (2009). Weapon selection using the AHP and TOPSIS methods under fuzzy environment. Expert Systems with Applications, 36 (4), 8143-8151.

[12] Gumus, Alev Taskin. (2009). Evaluation of hazardous waste transportation firms by using a two step fuzzy-AHP and TOPSIS methodology. Expert Systems with Applications, 36 (2), 4067-4074.

[13] Kahraman, Cengiz, Ruan, Da, \& Doğan, Ibrahim. (2003). Fuzzy group decision-making for facility location selection. Information Sciences, 157, 135-153.

[14] Kelemenis, Alecos, \& Askounis, Dimitrios. (2010). A new TOPSIS-based multi-criteria approach to personnel selection. Expert Systems with Applications, 37 (7), 4999-5008.

[15] Kulak, Osman, Durmuşoğlu, M Bülent, \& Kahraman, Cengiz. (2005). Fuzzy multi-attribute equipment selection based on information axiom. Journal of materials processing technology, 169 (3), 337-345.

[16] Mansor, Shattri, Ahmed, Nordin, Shiriff, Rashid, Al-shalabi, Mohamed A, Mansor, Shattri Bin, \& Ahmed, Nordin Bin. (2006). GIS Based Multicriteria Approaches to Housing Site Suitability Assessment. 
[17] Mehrabi Koshki, Ali. (2003). INDUSTRIAL FACILITIES LOCATION SELECTION OF BAHMANGROUP AUTOMOTIVE USING FUZZY TOPSIS. University Of TEHRAN.

[18] Melkote, Sanjay, \& Daskin, Mark S. (2001). Capacitated facility location/network design problems. European journal of operational research, 129 (3), 481-495.

[19] Momeni, Mansour. (2008). Modern Topics in Operations Research. Faculty of Management, Tehran University.

[20] Nanthavanij, Suebsak, \& Yenradee, Pisal. (1999). Predicting the optimum number, location, and signal sound level of auditory warning devices for manufacturing facilities. International Journal of Industrial Ergonomics, 24 (6), 569578.

[21] Roshan Milani, Karim. (2002). Airlines electricity distribution networks.

[22] Saaty, Thomas L. (1997). That is not the analytic hierarchy process: what the AHP is and what it is not. Journal of MultiCriteria Decision Analysis, 6 (6), 324-335.

[23] Satani, Nobuaki, Uchida, Akira, Deguchi, Atsushi, Ohgai, Akira, Sato, Seiji, \& Hagishima, Satoshi. (1998). Commercial facility location model using multiple regression analysis. Computers, environment and urban systems, 22 (3), 219-240.

[24] Torfi, Fatemeh, Farahani, Reza Zanjirani, \& Rezapour, Shabnam. (2010). Fuzzy AHP to determine the relative weights of evaluation criteria and Fuzzy TOPSIS to rank the alternatives. Applied Soft Computing, 10 (2), 520-528.

[25] Tsung-Yu, Chou, Chia-Lun, Hsu, \& Mei-Chyi, Chen. (2008). A fuzzy multi-criteria decision model for international tourist hotels location selection. International journal of hospitality management, 27 (2), 293-301.

[26] Yu, Chian-Son. (2002). A GP-AHP method for solving group decision-making fuzzy AHP problems. Computers \& Operations Research, 29 (14), 1969-2001.

[27] Yurdakul, Mustafa, \& Ic, Yusuf Tansel. (2004). AHP approach in the credit evaluation of the manufacturing firms in Turkey. International Journal of Production Economics, 88 (3), 269289.

[28] Zhang, Fengli, Johnson, Dana M, \& Sutherland, John W. (2011). A GIS-based method for identifying the optimal location for a facility to convert forest biomass to biofuel. Biomass and Bioenergy, 35 (9), 3951-3961. 